Article

\title{
Damage Indices and Photogrammetry for Decay Assessment of Stone-Built Cultural Heritage: The Case Study of the San Domenico Church Main Entrance Portal (South Calabria, Italy)
}

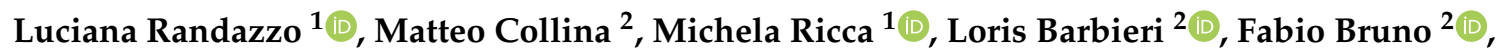 \\ Anna Arcudi ${ }^{3}$ and Mauro F. La Russa ${ }^{1,4, *}$ \\ 1 Department of Biology, Ecology and Earth Sciences (DiBEST), University of Calabria, \\ 87036 Arcavacata di Rende (CS), Italy; luciana.randazzo@unical.it (L.R.); michela.ricca@unical.it (M.R.) \\ 2 Department of Mechanical, Energy and Management Engineering (DIMEG), University of Calabria, \\ 87036 Arcavacata di Rende (CS), Italy; matteo.collina@unical.it (M.C.); loris.barbieri@unical.it (L.B.); \\ fabio.bruno@unical.it (F.B.) \\ 3 C.B.C. Conservazione Beni Culturali Società Cooperativa, 00185 Rome, Italy; anna.arcudi@libero.it \\ 4 Institute of Atmospheric Sciences and Climate, National Research Council, 40129 Bologna, Italy \\ * Correspondence: mauro.larussa@unical.it; Tel.: +39-0984-493535
}

Received: 8 May 2020; Accepted: 23 June 2020; Published: 25 June 2020

\begin{abstract}
In recent decades, increasing attention is being paid to the multidisciplinary approach that allows the performance of both a preventive conservation and a more invasive restoration action. In this context, the present study aims to acquire information and data from field surveys undertaken in San Domenico Church, Southern Calabria, in order to provide a tool for the recording and the inventory of damage and decay phenomena, and assess their causes and scale. The subsequent calculation of damage indices also provided useful information in order to allow the prioritization of conservation and preservation responses.
\end{abstract}

Keywords: Damage diagnosis; decay; photogrammetry; computer graphics; built heritage; Calabria; Italy

\section{Introduction}

As part of the activities related to the diagnosis, restoration, management, and valorization of cultural heritage $(\mathrm{CH})$, in the last decade, an increasing attention is being paid to the multidisciplinary approach that allows the performance of both a preventive conservation and more invasive restoration action, as well as a dissemination of cultural resources [1-3]. A proper preventive conservation goes through a planning process comprising diagnostics, restoration, and maintenance of cultural heritage [4]. With this in mind, there is a growing need to optimize both the diagnostic processes and the products currently used in the restoration practice, in order to make them more suitable for application in different environmental conditions. At the same time, there is a strong need to make cultural heritage useful and attractive in order to increase tourism [5]. As universally recognized by the normatives, institutions, and experts in the field, the conservation of cultural heritage must include: compatibility with the substrate/object guaranteeing the minimal intervention; reversibility and/or removability; identifiable restoration; multidisciplinary actions; and sustainability. The risk management of $\mathrm{CH}$ clearly involves different processes as planning, monitoring, maintenance, prevention, and restoration, and the coordination between them, should be achieved in order to reduce the potential damage or loss of $\mathrm{CH}$. Planned monitoring procedures should be adopted in sites of historical/archaeological 
interest in order to assess the potential decay and damage as functions of various factors such as external influences or internal chemical, and/or physical time-depending variations of characteristics of material [6,7]. Therefore, the whole process of risk assessment should combine detecting the specific active decay mechanism with an integrated study that should consider the type of decay and damage and the decay phenomenon mechanisms (kinetics, thermodynamics, structural) [8-10].

In this context, the present study was developed as a part of a wider research in the framework of the CRATI project-Conoscenza e Restauro Attraverso Tecnologie Avanzate Integrate (Knowledge and Restoration through Advanced Integrated Technologies). The project consists of a multidisciplinary diagnostic and conservation system using innovative methods (laboratory experimentation carried out on stone materials aimed at testing new products with consolidating properties, mainly physical) and, at the same time, developing an integrated ICT system for the management and valorization of the cultural heritage, applied to the Calabria region.

Proper data collection including history, the state of conservation, structural condition, all previous restoration works, as well as advanced diagnostics for the identification of vulnerability by environmental and human impact, was performed on a pilot site identified in San Domenico Church, located in the old town of Cosenza (South Calabria, Italy). The actual degradation processes involved were revealed by scientific methodologies [11].

Furthermore, the application of the photogrammetric survey and the analysis of degradation with the subsequent calculation of the damage indices (i.e., quantitative rating of damages according to [12]) was used in order to provide a reliable support for future monitoring and maintenance of the cultural heritage in line with United Nations' Sustainable Development Goal 11-“Make cities and human settlements inclusive, safe, resilient, and sustainable," and more specifically, the 11.4 goal— "Strengthen efforts to protect and safeguard the world's cultural and natural heritage" [13].

\section{Description of the Pilot Site: Historical Contexts}

The complex of the San Domenico Church, chosen as a case study, is one of the works of greatest historical interest in the old town of Cosenza (South Calabria, Italy), with a Gothic architectural imprint which, however, was modified over time during the Renaissance and Baroque periods. The façade consists of three parts: an upper part made up of the pediment (now no longer visible), which surrounds the tympanum, a central part where a rose window predominates, and a lower part occupied by a prothyrum with an acute arch and an external frame, probably dating back to the construction period of the complex.

The rose window is in a perfect state of conservation, built with tuff material. It has only assumed a thin gray-yellowish patina over time. The main entrance portal is made with an arch composed of large trapezoidal section blocks, with the exception of the triangular key segment and the rectangular section shutter segments, resting on polystyle pillars. The stone used for building the main entrance portal is a calcarenite, a medium-grained limestone, rather soft and easy to work, as confirmed by the results of scientific analyses carried out on 11 stone samples [11].

This material was extracted in the territory of the province of Cosenza, particularly rich in extractive areas. In particular, the leading quarries reported in the literature were essentially three: Mendicino, Altilia, and San Lucido. Among these, the quarry of San Lucido is reported as the site of the extraction of the lithoid material for the construction of the entrance portal of the church of San Domenico in Cosenza [14].

This calcarenite shows a carbonate matrix that can be defined as biocalcarenite/calcirudite [15] or biolitite/boundstone [16], with rare embedded clasts of igneous and metamorphic rocks, having sub-angular to rounded morphology. It is a porous but resistant material, with a variable chromaticity ranging from whitish to reddish hues. The heterogeneity of the content of ferrous minerals induces likely chromatic variations in the two varieties, although other causes cannot be excluded. 


\section{Materials and Methods}

\subsection{Photogrammetric Survey and 3D Reconstruction}

The two primary methods for digital 3D modeling are photogrammetry and 3D scanning. In fact, photogrammetry is a very effective method in acquiring 3D information and texture and it has been widely and efficiently applied in the cultural heritage field [17-21]. Terrestrial laser scanning has been largely adopted too, especially for 3D data collection of large and complex heritage objects [22-25]. As demonstrated and verified in several works [26-32] the use of one method rather than the other depends on the specific application case. For this specific case study, a correct and precise identification of the different degradation areas requires a high-resolution and high-quality textures. For this reason, photogrammetry has been preferred to 3D scanning techniques due to this lack of high-resolution textures. In fact, laser 3D scanners are equipped with a camera that is meant for data triangulation and not for the acquisition of high-resolution textures. It is possible to overcome this limitation by projecting external images, but this involves further steps in the post-processing phase of the 3D reconstruction process. Furthermore, photogrammetry allows faster execution than laser scanners since they are bulky and unwieldy and do not allow the user to easily acquire undercut areas. Lastly, the instruments required for photogrammetry are much cheaper than a laser scanner.

On the basis of the above-mentioned reasons, a standard photogrammetric technique was used in order to generate the 3D models of the entrance portal of the church of San Domenico in Cosenza. In particular, the photogrammetric survey has been carried out utilizing a Nikon D5100 reflex camera with a CMOS (Complementary Metal Oxide Semiconductor) sensor size of $(23.6 \times 15.6 \mathrm{~mm})$, a resolution of $4928 \times 3^{\cdot} 264 \mathrm{px}$, and equipped with Nikon $18-55 \mathrm{~mm}$ lens. No artificial source-lights have been used considering the dimensions and the natural illumination of the scene. The photo sets required enough overlap areas, at least around $60 \%$, in order to ensure automatic matching between homologous points, and a precise and accurate reconstruction of the entrance portal, even of the undercut areas. The photographic acquisition produced a dataset of 132 images, covering the area from different points of view with a mean ground sample distance (GSD) of $0.8(\mathrm{~mm} / \mathrm{px})$. To get the most details possible from the images, useful to identify and recognize the actual degradation processes that affect the stone used for building the main entrance portal, all the images were acquired in RAW format (.nef for Nikon cameras). Before proceeding with the reconstruction process, the dataset was subjected to an image enhancement process. In particular, the images were white-balanced, processed to recover the highlights and the shadows, and sharpened.

The reconstruction process was carried out by means of the commercial software Agisoft Metashape Pro. The workflow followed four stages: image alignment, dense point cloud generation, meshing, and texturing. In particular, the process started by using a structure-from-motion (SfM) algorithm to model the camera, aligning the images based on common features and calculating the position of the cameras in the space during the acquisition. The scaling was performed by means of a set of measures taken during the photographic survey using a Leica Disto X310 electronic distance measurement device. In particular, the average root-mean-square error (RMSE) in the scaling process was $0.002 \mathrm{~m}$. Based on these outcomes, a multi-view stereo (MVS) algorithm was used to calculate a depth-map and to generate a dense 3D point cloud of about 6.5 million points. To generate a solid model based on the acquired data, the point cloud was then meshed (Figure 1a).

Finally, the images acquired were projected to generate a high-detailed texture. The final textured 3D model, depicted in the following picture (Figure 1b), was refined, fixing small defects and holes produced during the meshing process. 

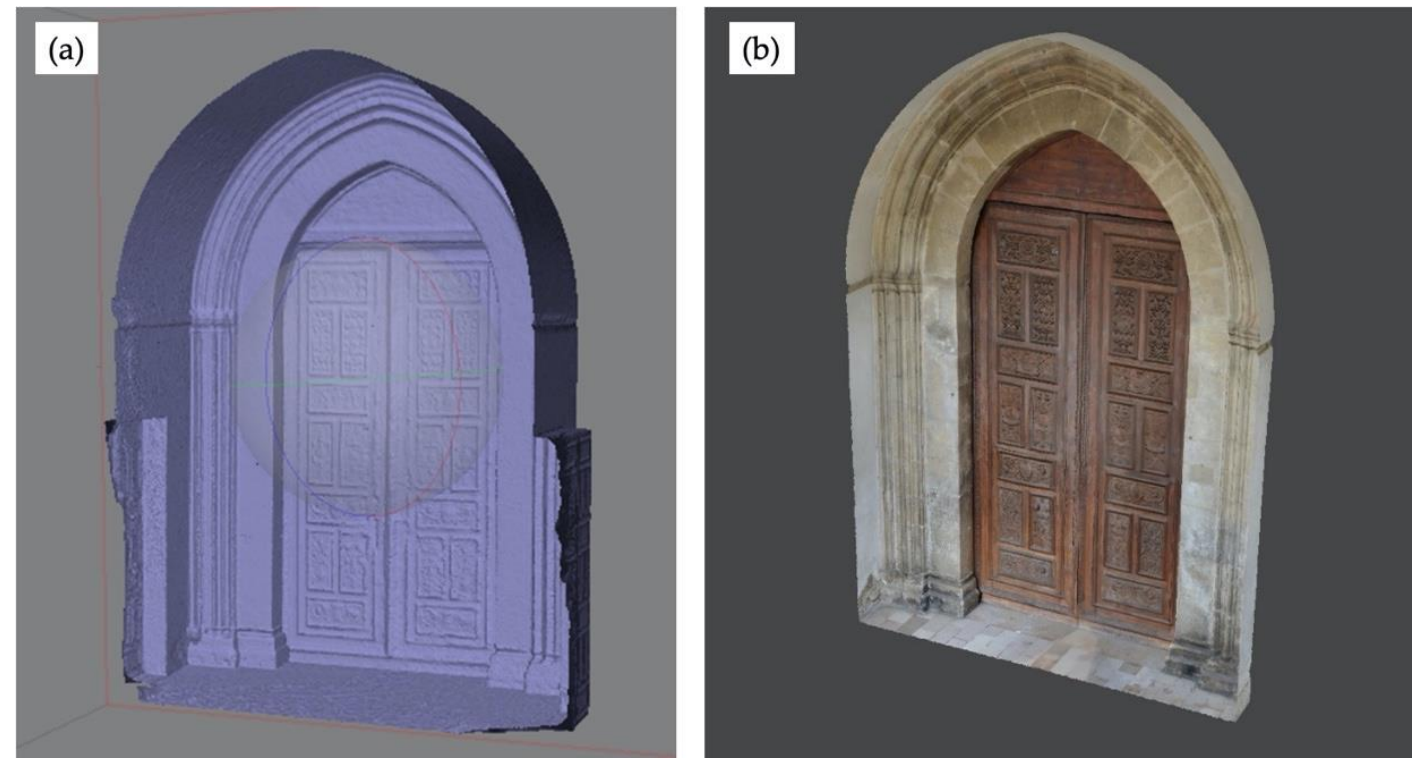

Figure 1. (a) The mesh model with no texture; (b) final 3D model with high-detailed texture.

\subsection{Damage Analysis}

The identification of decay processes and related degradation products on the selected pilot site allowed us to define the best conservation and restoration strategies and protocols. The first analytical phase allowed us to define the morphological-structural characteristics necessary for the definition of the state of conservation, that is, relationships between superficial decay forms and stone substrate. The obtained data created the basis for the calculation of the damage indices according to the model proposed by [12] (although adapted according to the specific features of the pilot site), returning a numerical evaluation of the degree of damage found on the investigated stone surfaces. This system, integrated with the 3D survey, allowed the identification of the most damaged architectural portions of the monument, in order to define a priority of intervention starting from the extent and severity of the detected degradation forms.

Systematic studies on the deterioration of stone materials must first define and consider the different scales of diagnosis and intervention in order to evaluate the degradation of materials as a whole. A first distinction is made on the basis of the macroscopic visibility of deterioration. According to [33], a first subdivision can be made into nanoscale $(<\mathrm{mm})$, microscale (from $\mathrm{mm}$ to $\mathrm{cm}$ ), mesoscale (from $\mathrm{cm}$ to $\mathrm{m}$ ), and macroscale (Table 1 ).

Table 1. Scale and parameters of decay phenomena (modified from [33]).

\begin{tabular}{|c|c|c|}
\hline \multicolumn{2}{|c|}{ Scale } & $\begin{array}{c}\text { Parameters for the Evaluation of Stone } \\
\text { Deterioration }\end{array}$ \\
\hline Non-visible deterioration & $\begin{array}{l}\text { Nanoscale } \\
(<\mathrm{mm})\end{array}$ & $\begin{array}{l}\text { Changes of stone properties and features } \\
\text { (composition, } \\
\text { texture, porosity, strength, etc.) }\end{array}$ \\
\hline \multirow[t]{3}{*}{ Visible deterioration } & $\begin{array}{c}\text { Microscale } \\
\text { (from mm to cm) }\end{array}$ & $\begin{array}{c}\text { Chromatic variation, } \\
\text { weight loss, } \\
\text { micromorphological variations }\end{array}$ \\
\hline & $\begin{array}{c}\text { Mesoscale } \\
\text { (from cm to m) }\end{array}$ & Deterioration phenomena-weathering forms \\
\hline & $\begin{array}{c}\text { Macroscale } \\
\text { (whole facade or building) }\end{array}$ & $\begin{array}{l}\text { Structural stability, } \\
\text { aesthetic appearance }\end{array}$ \\
\hline
\end{tabular}


In the specific case of this project, the mapping procedure of degradation forms was carried out at the level of the mesoscale and taking into consideration the identified deterioration phenomena and the alteration forms associated with it.

Two typologies of surveys were applied to the main entrance of the San Domenico Church (Figure 1), for an accurate damage diagnosis, following the procedure shown in Table 2 in order to obtain a lithological map (i.e., the stone materials used in the main entrance portal) and a weathering forms map according to the quantitative approach proposed by [12,34].

Table 2. Procedure adopted for the identification of weathering forms.

\begin{tabular}{ccc}
\hline & Diagnosis & \\
\hline & In situ Investigation & \\
\hline Monument Mapping \\
\hline Monument planimetry & Monument mapping & $\begin{array}{c}\text { Classification of lithotypes } \\
\text { Classification of weathering forms }\end{array}$ \\
\hline $\begin{array}{c}\text { Mlanimetry digitalization } \\
\text { lithological and } \\
\text { weathering forms map }\end{array}$ & $\begin{array}{c}\text { Acquired data: lithotypes, weathering } \\
\text { forms typologies, planimetric data }\end{array}$ & $\begin{array}{c}\text { Symbols adopted for lithology and } \\
\text { weathering forms }\end{array}$ \\
\hline $\begin{array}{c}\text { Maps: } \\
\text { damage categories }\end{array}$ & $\begin{array}{c}\text { Obtained data: lithotypes, damage } \\
\text { categories, planimetric data }\end{array}$ & $\begin{array}{c}\text { Quantitative evaluation: } \\
\text { lithology and } \\
\text { weathering forms }\end{array}$ \\
\hline
\end{tabular}

After the on-site inspection, sampling, and analysis, the data related to both lithological aspects and weathering forms were acquired, the latter were then related to the categories of damage, based on their severity and intensity. Six damage categories were defined: $0=$ no visible damage; $1=$ very slight damage, 2 = slight damage, 3 = moderate damage, $4=$ severe damage, $5=$ very severe damage. After that, the attribution of the decay intensity, which considers both qualitative and quantitative observations, was applied to each weathering forms in order to define damage indices, linear and progressive ones [12,34]. Such indices were calculated as follows:

$$
\begin{gathered}
\mathrm{DI}_{\text {lin }}=[(\mathrm{A} \times 0)+(\mathrm{B} \times 1)+(\mathrm{C} \times 2)+(\mathrm{D} \times 3)+(\mathrm{E} \times 4)+(\mathrm{F} \times 5)] / 100, \\
\mathrm{DI}_{\text {prog }}=\sqrt{ }\left[\left(\mathrm{A} \times 0^{2}\right)+\left(\mathrm{B} \times 1^{2}\right)+\left(\mathrm{C} \times 2^{2}\right)+\left(\mathrm{D} \times 3^{2}\right)+\left(\mathrm{E} \times 4^{2}\right)+\left(\mathrm{F} \times 5^{2}\right)\right] / 100
\end{gathered}
$$

where $\mathrm{A}=$ percentage area of damage category $0 ; \mathrm{B}=$ percentage area of damage category 1 , $\mathrm{C}=$ percentage area of damage category $2, \mathrm{D}=$ percentage area of damage category $3, \mathrm{E}=$ percentage area of damage category 4 , and $\mathrm{F}=$ percentage area of damage category 5 . Linear damage index $\left(\mathrm{DI}_{\text {lin }}\right)$ represents an average of all the highlighted damage categories, while progressive damage index $\left(\mathrm{DI}_{\text {prog }}\right)$ underlines damage associated with the damage categories of higher intensity or severity, in other words, it emphasizes the roles of the higher damage categories.

\section{Results and Discussion}

\subsection{D Mapping and Estimation of The Degradation Areas}

The 3D model of the entrance portal, generated by means of photogrammetric technique using high-detailed images, can then be adopted to both evaluate the structures in their entirety and their conservation status, and, furthermore, to recognize and identify the actual degradation processes. In fact, the 3D images associated with the photographic documentation allow a greater level of detail, leading to an easy and efficient identification of the different affected areas. 
To this end, an approach based on 3D imaging techniques was specifically developed in order to support restorers in performing the analysis of degradation and a precise calculation of the damage indices. The developed approach consists of four stages: preparation of the 3D model for the calculation of the damage indices; 3D mapping of the degradation areas; mesh generation and color-code grouping; and degradation area estimation.

In the specific case study, the process then started by cutting out the areas that were not useful for the calculation. For this reason, the wooden front door of the church, the floor, and side walls were removed from the 3D model (Figure 2). Subsequently, the 3D mapping, consisting of detecting and selecting the different degradation areas, was carried out by means of the open-source 3D computer graphics software Blender (www.blender.org). As abovementioned, in the 3D mapping stage, the high-detailed images acquired in the photogrammetry stage (Section 3.1) were adopted as a reference. In this manner, it is possible to precisely and efficiently recognize and select the different affected areas. To this end, the selection tools were used to draw directly on the 3D model and circumscribe the region of interest that was then duplicated to create a new mesh. In particular, the selection of the areas of interest was carried out by means a set of specific tools provided by Blender that allows to manual or automatic selection of the vertices, edges, and faces of the textured 3D mesh of the entrance portal. A mixed approach was adopted, in which the image selection mode, that automatically selects all faces that use the same UV texture, and the lasso select tool, that allows manual creation of a free-form selection, were used to select the various areas related to a specific degradation form, which were then duplicated and joined to create a new mesh. This operation is depicted in the following figure (Figure 2) in which the chromatically altered regions of the entrance portal were recognized, circumscribed, and then were duplicated by generating new mesh objects. It is worth noticing that a very small offset, in the millimeters scale, was applied to the new mesh in order to visualize it over the original 3D model.

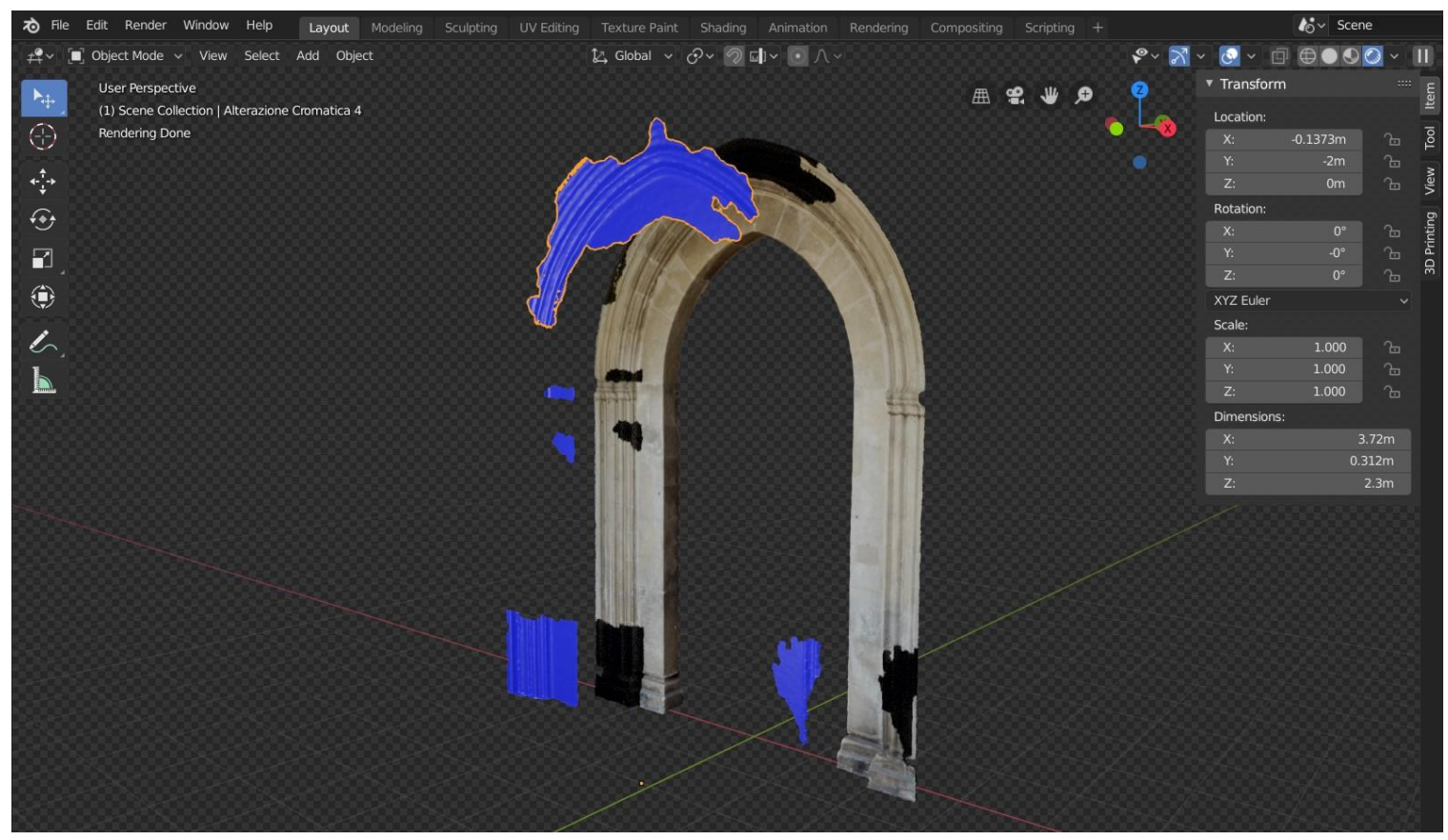

Figure 2. 3D model of the entrance portal and mesh generation of the chromatically altered regions.

Every small new mesh was then organized and grouped, by means of the collecting tools and options provided in Blender, and was colored according to the degradation group to which it belongs. This technique permits the user to turn on and off the visualization of every kind of degradation 
class to better visualize the information needed and possibly to set a transparency level in order to simultaneously display multiples class of degradations.

The following figure (Figure 3) depicts the four different degradation forms (a-d) that were detected on the entrance portal. Each degradation is represented by a specific color assigned in the grouping stage. In particular, this assignment is performed by customizing the material properties, i.e., color and transparency level, of the mesh.

(a)

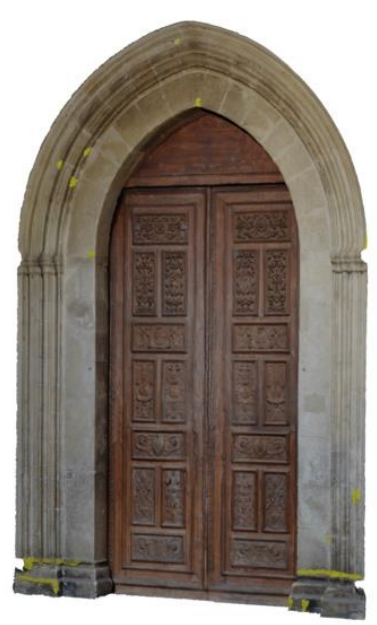

(c)

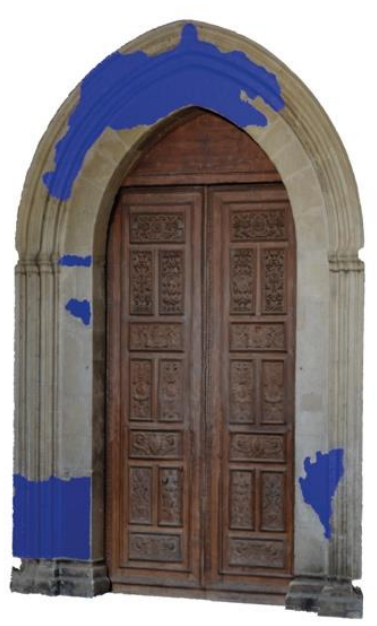

(b)

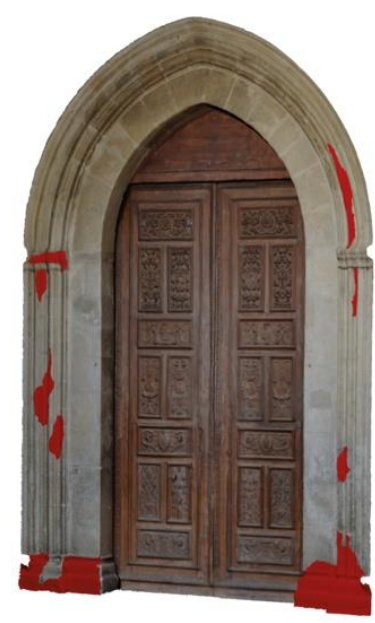

(d)

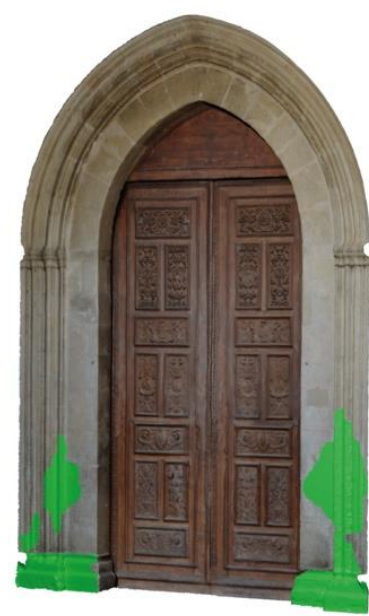

Figure 3. 3D mapping of the four degradation areas: (a) loss of material; (b) erosion; (c) chromatic alteration; (d) black crusts.

The proposed approach ends with the calculation of the degradation areas. To this end, considering that every form of deterioration is represented by a mesh, or a group of meshes, it is possible to quickly and accurately calculate their surface. The following table (Table 3) provides the estimation of the degradation areas identified on the entrance portal, which has a surface of $263^{\circ} 668.8 \mathrm{~cm}^{2}$.

Table 3. Degradation areas calculation.

\begin{tabular}{cccc}
\hline Loss of Material & Erosion & Chromatic Alteration & Black Crusts \\
\hline $2^{\circ} 997.0 \mathrm{~cm}^{2}$ & $23^{\circ} 127.1 \mathrm{~cm}^{2}$ & $55^{\circ} 199.5 \mathrm{~cm}^{2}$ & $34^{\circ} 245.4 \mathrm{~cm}^{2}$ \\
\hline
\end{tabular}

\subsection{Weathering Forms and Related Damage Categories and Indices}

The architectural element chosen for the survey and the mapping of the weathering forms permitted the collection of data useful for planning restoration interventions that can be applied in 
the future on the whole facade of the church (Figure 4a). Moreover, obtained data will also be used for testing new restoration products specifically selected and suitable for the recognized building material. Firstly, with the aid of the macroscopic field investigation corroborated by subsequent laboratory investigations, it was possible to identify different forms of alteration (the used lexicon follows the Italian normative [35]) such as superficial deposits, black crusts sometimes associated with oxalate patinas, erosion/loss of materials, chromatic alteration, and cracks. During field survey, visible alteration forms were identified and localized on the 2D architectural drawing section of the main façade. In some places, the sampling was carried out to recognize the nature (in terms of chemical and mineralogical composition) of the alteration forms and substrates (for more details about the performed analytical investigations and the corresponding results, see the reference [11]). A brief description of the weathering forms with some details about location and appearance follows. Superficial deposits, i.e., accumulation of materials of various kinds on the whole surface of the main entrance (dust, soil, etc.) are present due to its outdoor exposure to atmospheric pollutants (combustion products, suspended particulates and fine particles of geogenic origin, etc) were identified (Figure $4 \mathrm{~b}$ ). Also, the roughness of the surface stone plays an important role in the accumulation phenomenon. Moreover, the formation of black crusts, a phenomenon already detected in the preliminary observation phase and confirmed by scientific analyses [11] happens mainly at the foot of the portal in correspondence with the bases of the pillars. In some areas together with the black crusts, the presence of oxalates was also detected. In the lower part of the portal, probably due to associated phenomena of a chemical-physical nature, erosion occurs more often in correspondence with the areas affected by black crusts (Figure $4 c, d$ ). This occurs because under the black crusts, in particular, the cohesion of building stone is significantly reduced, demonstrating that the crust represents a real risk for stone conservation. The alteration of the color characteristics (hue, chrome, saturation) of the stone material is concentrated in particular in the final zone of the arch and in the medium-low part of the portal, but it is in general distributed over large areas (Figure 4c). The loss of material as small shortcomings of stone that interrupt the trend of the geometric lines of the portal can be identified and is particularly concentrated in the lower part, where there is a jagged loss of portion of material along the columns and base stones (Figure 4e). In areas of simultaneous chromatic alteration of the surface, the presence of a thin biological patina (Figure 4c) adherent to the substrate was highlighted. Its nature will be explored with the aid of biological scientific analyses. Finally, some important fractures of the segments of the base stones are identified always at the lower part of the portal pillars (Figure 4f). The greatest incidence of degradation forms in the basal part of the monument could also be due to capillary rising/humidity phenomena that favor the circulation of water, triggering chemical-physical reactions that, in general, further cause the building materials to deteriorate.

These weathering forms fall into the following groups, identified and recognized in the literature [12,34]:

- Group I: loss of stone material;

- Group II: chromatic alteration/deposits;

- Group III: detachment;

- Group IV: cracks/deformation.

Table 4 shows the quantitative evaluation of the weathering forms according to their intensity.

At this point, the damage indices are computed for the final quantification and evaluation of damage on the selected monument. The calculation of the damage indices is based on the quantifiable assessment of the categories of damage, ensuring, therefore, a scientific quantification about the conservation state of this portion of the monument. According to the calculation methods, both damage indices are between 0 and 5.0. Based on the specificities of the selected site, it shows a linear damage index equal to 1.0 while the progressive damage index is equal to 1.6.

In conclusion, the main entrance of the San Domenico Church appears to be affected by damage ranging from no visible deterioration (damage category 0 ) to moderate (damage category 3 ). 
In particular, the highest category of damage (moderate damage) was attributed to the areas affected by chromatic alteration associated with the presence of biological patinas and black crusts, which over time can lead to severe material loss and deep progression of degradation.

In general, an increase in the damage indices corresponds to a growing need and urgency for intervention. The linear and progressive damage indices must be considered jointly, due to the need for rating and urgency of intervention.
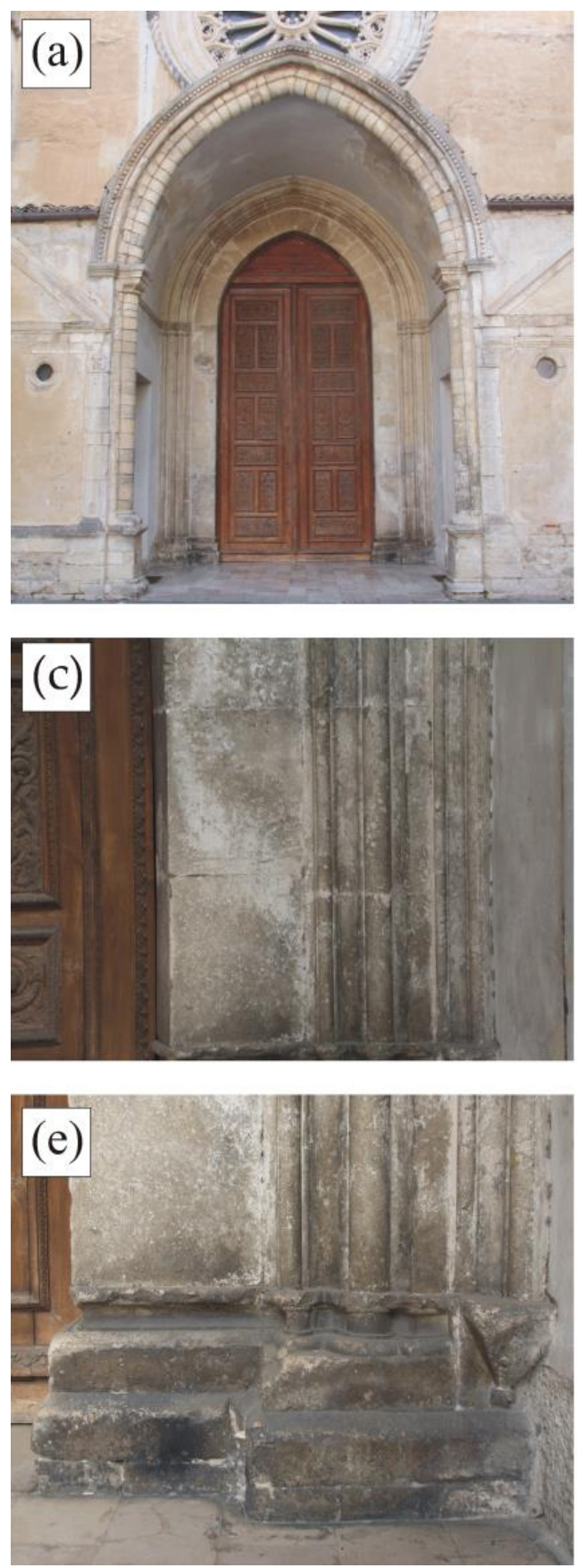
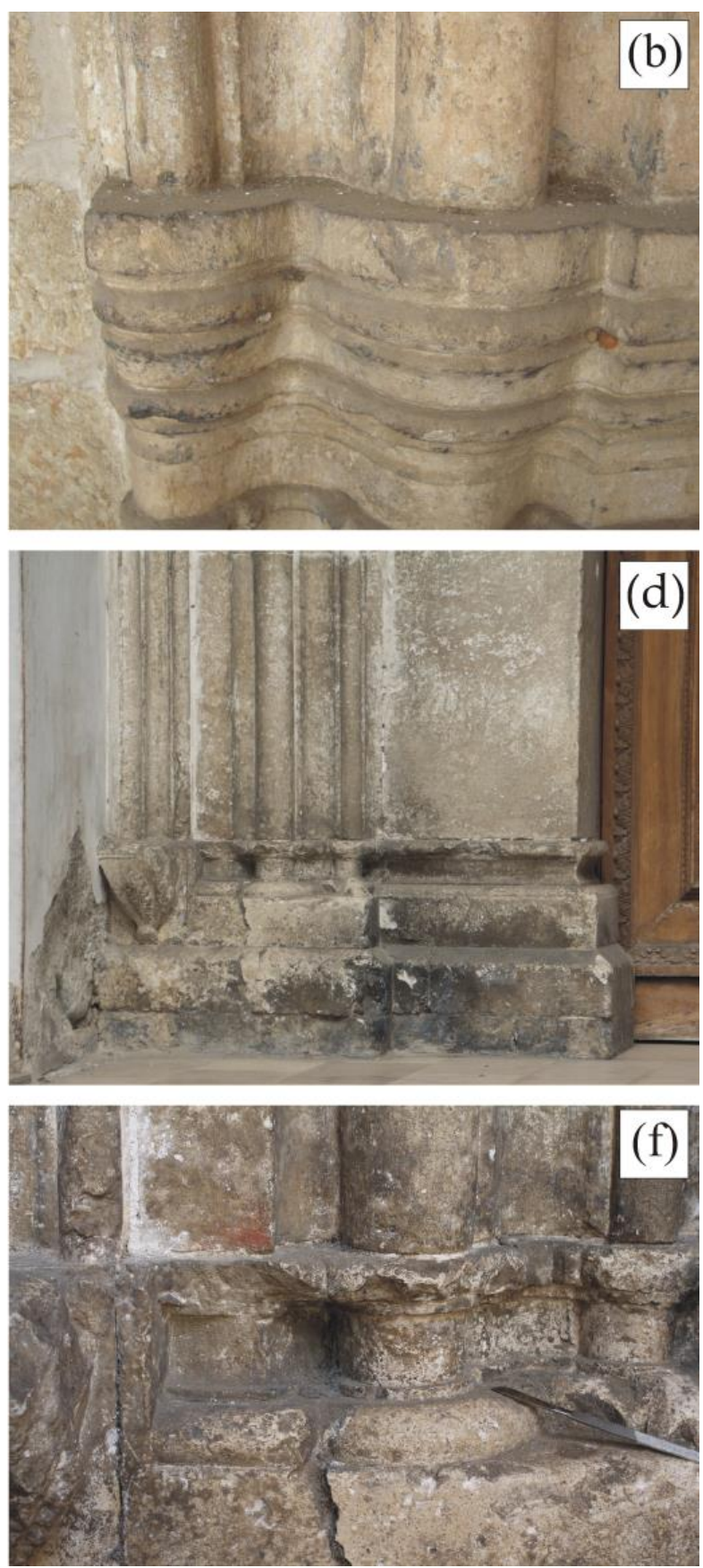

Figure 4. (a) Main entrance of the San Domenico Church; (b) superficial deposits; (c) chromatic alteration associated with biological patina; (d-f) combination of black crusts, loss of material and fractures. 
Table 4. Evaluation of the weathering forms and intensity parameters.

\begin{tabular}{|c|c|c|c|c|c|c|c|}
\hline Weathering Forms & & \multicolumn{6}{|c|}{ Intensity Evaluation Parameters } \\
\hline \multirow{4}{*}{ Superficial deposits } & \multirow{3}{*}{ Intensity } & \multicolumn{6}{|c|}{ Covering degree of the surface $(\%)$-Thickness $(\mu \mathrm{m}-\mathrm{mm})$} \\
\hline & & $<10$ & 25 & \multicolumn{2}{|c|}{50} & 75 & 100 \\
\hline & & $0.01-0.05$ & $0.05-0.1$ & \multicolumn{2}{|c|}{$0.1-0.5$} & $0.5-1 \mathrm{~mm}$ & $>1 \mathrm{~mm}$ \\
\hline & Damage categories & 0 & 1 & 2 & 3 & 4 & 5 \\
\hline \multirow{4}{*}{$\begin{array}{c}\text { Black crusts and } \\
\text { associated oxalate } \\
\text { patinas }\end{array}$} & & \multicolumn{6}{|c|}{ Covering degree of the surface $(\%)$-Thickness $(\mu \mathrm{m}-\mathrm{mm})$} \\
\hline & & $<15$ & 25 & \multicolumn{2}{|c|}{50} & 75 & 100 \\
\hline & Intensity & $0.01-0.05$ & $0.05-0.1$ & \multicolumn{2}{|c|}{$0.1-0.5$} & $0.5-1 \mathrm{~mm}$ & $>1 \mathrm{~mm}$ \\
\hline & Damage categories & 0 & 1 & 2 & 3 & 4 & 5 \\
\hline \multirow{3}{*}{ Erosion } & & \multicolumn{6}{|c|}{ Depth (mm and/or cm) } \\
\hline & Intensity & $<0.5$ & $0.5-1$ & $1-3$ & $3-5$ & $5-10$ & $10-25$ \\
\hline & Damage categories & 0 & 1 & 2 & 3 & 4 & 5 \\
\hline \multirow{4}{*}{ Chromatic alteration } & & \multicolumn{6}{|c|}{ Covering degree of the surface $(\%)$-Color change } \\
\hline & \multirow{2}{*}{ Intensity } & $<10$ & 25 & \multicolumn{2}{|c|}{50} & 75 & 100 \\
\hline & & \multicolumn{3}{|c|}{ Pigmentation } & \multicolumn{3}{|c|}{ Whitening } \\
\hline & Damage categories & 0 & 1 & 2 & 3 & 4 & 5 \\
\hline \multirow{3}{*}{ Loss of material } & & \multicolumn{6}{|c|}{ Covering degree of the surface $(\%)$} \\
\hline & Intensity & $<10$ & 25 & & & 75 & 100 \\
\hline & Damage categories & 0 & 1 & 2 & 3 & 4 & 5 \\
\hline \multirow{3}{*}{ Cracks } & & \multicolumn{6}{|c|}{ Covering degree of the surface (\%) } \\
\hline & Intensity & $<10$ & 25 & & & 75 & 100 \\
\hline & Damage categories & 0 & 1 & 2 & 3 & 4 & 5 \\
\hline
\end{tabular}

\section{Conclusions}

The identification, analysis, quantitative distribution of decay forms, and related state of conservation represent the first essential approach for a correct risk management of any monument that has to be maintained.

Gradual and cumulative processes (such as chemical, physical, or biological degradation) could result in loss of value to the heritage asset. Therefore, a prioritization of conservative interventions should be achieved and provided to heritage managers and custodians in order to make good decisions about protection of the cultural heritage.

The analytical approach followed in this study for the assessment of susceptibility to deterioration phenomena of San Domenico Church proved particularly effective. The use of quick and safe photogrammetric survey provided a high-resolution images collection for the further quantitative analysis of building materials and related deterioration evaluation.

As far as the state of conservation is concerned, the building materials of San Domenico Church main entrance are affected by decay phenomena related both to their petrographic features and the environmental conditions.

According to the analytical results followed for the evaluation of damage categories, San Domenico Church is affected by a non-visible deterioration to a moderate damage, with heterogeneous distribution as suggested by damage indexes.

This survey represents a comprehensive example of anamnesis of a monument, and damage diagnosis, leading to important practical concerns for an acceptable making-decision process to be applied in restoration and conservation practice. 
Author Contributions: Conceptualization, M.F.L.R.; methodology, F.B., M.C. and L.B.; software, F.B., M.C. and L.B.; formal analysis, L.R., M.R. and A.A.; investigation, L.R., M.R. and A.A.; writing-original draft preparation, L.R.; writing-review and editing, L.R. and M.R.; funding acquisition, M.F.L.R. All authors have read and agreed to the published version of the manuscript.

Funding: This research was funded by the Calabria Region in the framework of the project POR CALABRIA FESR-FSE 2014-2020. ASSE I-PROMOZIONE DELLA RICERCA E DELL'INNOVAZIONE Obiettivo specifico 1.2 - "Rafforzamento del sistema innovativo regionale e nazionale" Azione 1.2.2— "Supporto alla realizzazione di progetti complessi di attività di ricerca e sviluppo su poche aree tematiche di rilievo e all'applicazione di soluzioni tecnologiche funzionali alla realizzazione delle strategie di S3". CUP: J68C17000100006

Conflicts of Interest: The authors declare no conflicts of interest.

\section{References}

1. ICOMOS. International Charter for the Conservation and Restoration of Monuments and Sites; ICOMOS: Venice, Italy, 1964.

2. ICOMOS. The Athens Charter for the Restoration of Historic Monuments-1931. Available online: https://www.icomos.org/en/167-the-athens-charter-for-the-restoration-of-historic-monuments (accessed on 11 November 2011).

3. Jouan, P.; Hallot, P. Digital Twin: Research Framework to Support Preventive Conservation Policies. Int. J. Geo-Inf. 2020, 9, 228. [CrossRef]

4. Binda, L.; Saisi, A.; Tiraboschi, C. Investigation Procedures for the diagnosis of the historic masonries. Construct. Build. Mater. 2000, 14, 199-233. [CrossRef]

5. Timothy, D.J.; Gyan, P.N. Cultural Heritage and Tourism in the Developing World: A Regional Perspect; Routledge Taylor \& Francis Group: Abingdon-on-Thames, UK, 2009; p. 260.

6. Camuffo, D. Microclimate for Cultural Heritage; Elsevier: Amsterdam, The Netherlands, 1998.

7. Camuffo, D.; Fassina, V.; Havermans, J. Basic Environmental Mechanisms Affecting Cultural Herit; Nardini Editore: Firenze, Italy, 2010.

8. Moropoulou, A.; Kioussi, A.; Karoglou, M.; Bakolas, A.; Georgousopoulos, G.; Chronopoulos, M. Innovative protocols for integrated diagnostics on historic materials and structures. In Structural Faults and Repair; Radonjanin, V., Crews, K., Eds.; University of Edinburgh: Edinburgh, UK, 2012; pp. 397-399.

9. Kioussi, A.; Labropoulos, K.; Karoglou, M.; Moropoulou, A.; Zarnic, R. Recommendations and strategies for the establishment of a guideline for monument documentation harmonized with the existing European standards and codes. J. Geoinf. FCE CTU 2011, 6, 178-184. [CrossRef]

10. Antonelli, F.; Lazzarini, L.; Cancelliere, S.; Tesser, E. Study of the deterioration products, gilding, and polychromy of the stones of the Scuola Grande Di San Marco's façade in Venice. Stud. Conserv. 2016, 61, 74-85. [CrossRef]

11. Ricca, M.; Le Pera, M.; Licchelli, M.; Macchia, A.; Malagodi, M.; Randazzo, L.; Rovella, N.; Ruffolo, S.A.; Weththimuni, M.L.; La Russa, M.F. The CRATI Project: New Insights on the Consolidation of Salt Weathered Stone and the Case Study of San Domenico Church in Cosenza (South Calabria, Italy). Coatings 2019, 9, 330. [CrossRef]

12. Fitzner, B.; Heinrichs, K.; La Bouchardiere, D.; Galan, E.; Zezza, F.P.O. Damage index for stone monuments. In Proceedings of the 5th International Symposium on the Conservation of Monuments in the Mediterranean Basin, Sevilla, Spain, 5-8 April 2000.

13. Sustainable Development Goals 11. Make Cities and Human Settlements Inclusive, Safe, Resilient and Sustainable. Available online: www.un.org/sustainabledevelopment/cities/ (accessed on 15 February 2020).

14. Lico, A. Materiali lapidei e cave di approvvigionamento degli scalpellini roglianesi: Risorse in Calabria e nella Provincia di Cosenza. In La Pietra, Il Mestiere e l'arte del Decorare. Storia della Lavorazione della Pietra Nella Provincia di Cosenza; Pellegrini Editore: Cosenza, Italy, 2015; pp. 74-91.

15. Mastrandrea, A.; Muto, F.; Neri, C.; Papazzoni, C.A.; Perri, E.; Russo, F. Deep-Water Coral Banks: An Example from the "Calcare di Mendicino" (Upper Miocene, Nothern Calabria, Italy). Facies 2012, 47, 27-42. [CrossRef]

16. Crisci, G.M.; De Francesco, A.M.; Gattuso, C.; Miriello, D. Un metodo geochimico per la determinazione della provenienza di lapidei macroscopicamente omogenei. Un esempio di applicazione sui monumenti del centro storico di Cosenza. Arkos Sci. Restaur. Archit. 2012, 2, 52-59.

17. Georgopoulos, A.; Ioannidis, C. Photogrammetric and surveying methods for the geometric recording of archaeological monuments. In Proceedings of the FIG Working Week 2004, Athens, Greece, 22-27 May 2004. 
18. Yilmaz, H.M.; Yakar, M.; Yildiz, F. Documentation of historical caravansaries by digital close range photogrammetry. Autom. Constr. 2008, 17, 489-498. [CrossRef]

19. Earl, G.; Beale, G.; Martinez, K.; Pagi, H. Polynomial texture mapping and related imaging technologies for the recording, analysis and presentation of archaeological materials. Int. Arch. Photogramm. Remote Sens. Spat. Inf. Sci. 2010, 38, 218-223.

20. Dostal, C.; Yamafune, K. Photogrammetric texture mapping: A method for increasing the Fidelity of 3D models of cultural heritage materials. J. Archaeol. Sci. Rep. 2018, 18, 430-436. [CrossRef]

21. Bruno, F.; Barbieri, L.; Muzzupappa, M.; Tusa, S.; Fresina, A.; Oliveri, F.; Lagudi, A.; Cozza, A.; Peluso, R. Enhancing learning and access to Underwater Cultural Heritage through digital technologies: The case study of the "Cala Minnola" shipwreck site. Digit. Appl. Archaeol. Cult. Herit. 2019, 13, 1-9. [CrossRef]

22. Doulamis, A.; Voulodimos, A.; Protopapadakis, E.; Doulamis, N.; Makantasis, K. Automatic 3D Modeling and Reconstruction of Cultural Heritage Sites from Twitter Images. Sustainability 2020, 12, 4223. [CrossRef]

23. Abmayr, T.; Härtl, F.; Reinköster, M.; Fröhlich, C. Terrestrial laser scanning: Applications in cultural heritage conservation and civil engineering. In Proceedings of the ISPRS Working Group V/4, Venice, Italy, 22-24 August 2005.

24. Noor, N.M.; Kamaruddin, Z.; Abdullah, A.; Abdullah, A.A.; Eusoff, S.S.; Mustafa, M.H. Using terrestrial laser scanner for Malay heritage documentation: preliminary approach to Istana Balai Besar, Kelantan. Int. J. Dev. Sustain. 2018, 7, 1886-1897.

25. Lezzerini, M.; Antonelli, F.; Columbu, S.; Gadducci, R.; Marradi, A.; Miriello, D.; Parodi, L.; Secchiari, L.; Lazzeri, A. Cultural Heritage Documentation and Conservation: Three-Dimensional (3D) Laser Scanning and Geographical Information System (GIS) Techniques for Thematic Mapping of Facade Stonework of St. Nicholas Church (Pisa, Italy). Int. J. Archit. Herit. 2016, 10, 9-19. [CrossRef]

26. Kushwaha, S.K.; Dayal, K.R.; Raghavendra, S.; Pande, H.; Tiwari, P.S.; Agrawal, S.; Srivastava, S.K. 3D Digital Documentation of a Cultural Heritage Site Using Terrestrial Laser Scanner-A Case Study. In Applications of Geomatics in Civil Engineering; Ghosh, J.K., da Silva, I., Eds.; Springer: Singapore, 2020; pp. 49-58.

27. Böhler, W.; Marbs, A. 3D scanning and photogrammetry for heritage recording: A comparison. In Proceedings of the 12th International Conference on Geoinformatics, Gävle, Sweden, 7 June 2004; pp. 291-298.

28. Yastikli, N. Documentation of cultural heritage using digital photogrammetry and laser scanning. J. Cult. Herit. 2007, 8, 423-427. [CrossRef]

29. Grussenmeyer, P.; Landes, T.; Voegtle, T.; Ringle, K. Comparison methods of terrestrial laser scanning, photogrammetry and tacheometry data for recording of cultural heritage buildings. Int. Archiv. Photogramm. Remote Sens. Spat. Inf. Sci. 2008, 37, 213-218.

30. Barsanti, S.G.; Remondino, F.; Visintini, D. Photogrammetry and Laser Scanning for archaeological site 3D modeling-Some critical issues. In Proceedings of the 2nd Workshop on the New Technologies for Aquileia, Aquileia, Italy, 25 June 2012.

31. Costa, E.; Balletti, C.; Beltrame, C.; Guerra, F.; Vernier, P. Digital survey techniques for the documentation of wooden shipwrecks. Int. Archiv. Photogramm. Remote Sens. Spat. Inf. Sci. 2016, 41, 237-242. [CrossRef]

32. Alshawabkeh, Y.; El-Khalili, M.; Almasri, E.; Bala'awi, F.; Al-Massarweh, A. Heritage documentation using laser scanner and photogrammetry. The case study of Qasr Al-Abidit, Jordan. Digit. Appl. Archaeol. Cult. Herit. 2020, 16, e00133. [CrossRef]

33. Viles, H.A.; Camuffo, D.; Fitz, S.; Fitzner, B.; Lindquist, O.; Livingston, R.A.; Maravellaki, P.V.; Sabbioni, C.; Warscheid, T. Group report: What is the state of our knowledge of the mechanisms of deterioration and how good are our estimates of rates of deterioration. In Report of the Dahlem Workshop on Saving Our Architectural Heritage: The Conservation of Historic Structures, Berlin, 3-8 March 1996; Baer, N.S., Snethlage, R., Eds.; John Wiley \& Sons Ltd.: Hoboken, NJ, USA, 1997; pp. 95-112.

34. Fitzner, B. Documentation and evaluation of stone damage on monuments. In Proceedings of the 10th International Congress on Deterioration and Conservation of Stone, Stockholm, Sweden, 27 June-2 July 2004; pp. 677-690.

35. Raccomandazioni NorMal-1/88. Alterazioni Macroscopiche dei Materiali Lapidei: Lessico; CNR-ICR: Rome, Italy, 1988.

(C) 2020 by the authors. Licensee MDPI, Basel, Switzerland. This article is an open access article distributed under the terms and conditions of the Creative Commons Attribution (CC BY) license (http://creativecommons.org/licenses/by/4.0/). 